\title{
BMJ Open Neck circumference and clustered cardiovascular risk factors in children and adolescents: cross-sectional study
}

\author{
José Castro-Piñero, ${ }^{1}$ Alvaro Delgado-Alfonso, ${ }^{1}$ Luis Gracia-Marco, ${ }^{2,3}$ \\ Sonia Gómez-Martínez, ${ }^{4}$ Irene Esteban-Cornejo, ${ }^{5,6}$ Oscar L Veiga, ${ }^{5}$ \\ Ascensión Marcos, ${ }^{4}$ Víctor Segura-Jiménez, ${ }^{1}$ The UP\&DOWN Study Group
}

To cite: Castro-Piñero J, Delgado-Alfonso A, GraciaMarco L, et al. Neck circumference and clustered cardiovascular risk factors in children and adolescents: crosssectional study. BMJ Open 2017;7:e016048. doi:10.1136/ bmjopen-2017-016048

- Prepublication history and additional material for this paper are available online. To view these files please visit the journal online (http://dx.doi. org/10.1136/bmjopen-2017016048).

Received 19 January 2017 Revised 19 May 2017 Accepted 8 June 2017

CrossMark

For numbered affiliations see end of article.

Correspondence to Dr José Castro-Piñero; jose.castro@uca.es

\section{ABSTRACT}

Objective Early detection of cardiovascular disease (CVD) risk factors, such as obesity, is crucial to prevent adverse long-term effects on individuals' health. Therefore, the aims were: (1) to explore the robustness of neck circumference (NC) as a predictor of CVD and examine its association with numerous anthropometric and body composition indices and (2) to release sex and agespecific NC cut-off values to classify youths as overweight/ obese.

Design Cross-sectional study.

Setting 23 primary schools and 17 secondary schools from Spain.

Participants 2198 students (1060 girls), grades 1-4 and 7-10.

Measures Pubertal development, anthropometric and body composition indices, systolic and diastolic blood pressure (SBP and DBP, respectively), cardiorespiratory fitness, blood sampling triglycerides (TG), total cholesterol (TC), high-density lipoprotein cholesterol (HDL-C), lowdensity lipoprotein cholesterol (LDL-C), glucose and inflammatory markers. Homoeostasis model assessment (HOMA-IR) and cluster of CVD risk factors were calculated.

Results NC was positively correlated with all anthropometric and body composition indices. NC was negatively associated with maximum oxygen consumption $\left(R^{2}=0.231, p<0.001\right.$ for boys; $R^{2}=0.018, p<0.001$ for girls) and positively associated with SBP, DBP, TC/HDL-C, TG, HOMA, complement factors C-3 and C-4, leptin, adiponectin and clustered CVD risk factor in both sexes ( $R^{2}$ from 0.035 to $0.353, p<0.01$ for boys; $R^{2}$ from 0.024 to $0.215, p<0.001$ for girls). Moreover, NC was positively associated with serum $C$ reactive protein, $L D L-C$ and visfatin only in boys ( $R^{2}$ from 0.013 to $0.107, p<0.05$ ). Conclusion NC is a simple, low-cost and practical screening tool of excess of upper body obesity and CVD risk factors in children and adolescents. Paediatricians can easily use it as a screening tool for overweight/obesity in children and adolescents. For this purpose, sex and agespecific thresholds to classify children and adolescents as normal weight or overweight/obese are provided.

\section{BACKGROUND}

Obesity is a disease affecting people of all ages, sex, ethnicities and socioeconomic levels ${ }^{1}$ with serious public health

\section{Strengths and limitations of this study}

- The use of a large number of anthropometric and body composition indices, as well as cardiometabolic risk factors and inflammatory markers is a strength of this study.

- The study sample consisted of children and adolescents with different weight status, thus broadening the applicability of the findings.

- The cross-sectional nature of the study limits the establishment of causality.

- The study group consisted of a single ethnic group (white Caucasian) and the cut-off values herein provided may not be valid for other ethnic groups.

- More accurate measures of overweight/obesity (eg, those obtained with MRI or dual energy X-ray absorptiometry) might be used to assess the association with NC.

implications. Particularly, overweight and obesity in children and adolescents are a pandemic worldwide, affecting not only developed but also developing countries. ${ }^{2}$ Excess body fat in children and adolescents is associated with cardiovascular-related risk factors such as type II diabetes, insulin resistance, hypertension, elevated triglyceride and cholesterol levels. ${ }^{3}$ The presence of cardiovascular disease (CVD) risk factors in childhood is associated with premature death in adulthood. ${ }^{4}$ Consequently, early detection of CVD risk factors, such as obesity, is crucial to prevent adverse long-term effects on individuals' health. ${ }^{5}$

Practical and simple anthropometric and body composition indices such as body mass index (BMI), waist circumference (WC), waistto-hip ratio, waist-to-height ratio (WHtR) and body fat percentage (BFP) are widely used as indices of total and central obesity. Indeed, some of these indices have been taken into account in the Assessing Levels of PHysical Activity (ALPHA) health-related fitness test 
battery, which is nowadays the most relevant health-related fitness test battery for children and adolescents. ${ }^{6}$

Recent researchers have proposed the neck circumference (NC) as another screening tool of CVD risk factors (ie, obesity) in children and adolescents. ${ }^{7-11}$ However, these studies examine this association through single cardiometabolic risk factors (ie, insulin resistance, hypertension and hyperlipidaemia (triglyceride and cholesterol). Clustering of CVD risk factors seems to be a much stronger measure of cardiovascular health in children and adolescents than single risk factors, as a subject with cardiovascular risk may reflect high levels of several risk factors simultaneously. ${ }^{12}$ Additionally, inflammatory markers have recently received close attention and are considered 'emerging CVD risk factors'. ${ }^{13}$ Previous studies have identified some inflammatory markers (such as complement factors C-3 and C-4, C reactive protein, adiponectin, leptin, interleukin 6 , tumour necrosis factor alpha and visfatin) to play a key role in CVD development in children, ${ }^{14}$ adolescents ${ }^{14}$ and adults. ${ }^{15}$ However, whether $\mathrm{NC}$ is associated with inflammatory markers in children and adolescents is still unknown in spite of its clinical relevance as so it is the potential usefulness of $\mathrm{NC}$ as a predictor for CVD risk factors.

Therefore, the aims were: (1) to explore the robustness of $\mathrm{NC}$ as a predictor of CVD and examine its association with numerous anthropometric and body composition indices and (2) to release sex-age-specific NC cut-off values to classify youths as overweight/obese, based on prediction equations using BMI, WC and BFP.

\section{METHODS}

\section{Study design, setting and participants}

Participants selected for this cross-sectional study were enrolled in the UP\&DOWN study. ${ }^{16}$ In brief, the UP\&DOWN study was a 3-year longitudinal study designed to assess the impact of physical activity and sedentary behaviours over time on health indicators as well as to identify the psychoenvironmental and genetic determinants of physical activity in a Spanish sample of children and adolescents. Data from the present study were collected from September 2011 to June 2012. Children and adolescents were recruited from schools in Cádiz and Madrid, respectively. A total convenience sample of 2225 participants aged 6 to 18 years participated in the UP\&DOWN study although the present study includes 2198 participants (1060 girls) with complete data at baseline on anthropometric and body composition indices. According to the database of the Spanish Institute of National Statistics, our sample size represented the $50 \%$ $(n=1179)$ and $5 \%(n=1019)$ of the total population size of school children and adolescents, respectively, with a 3\% percentage of error for both sample sizes. Blood sampling was randomly performed in one-fourth of the recruited children and adolescents (514; 244 girls).

Parents and school supervisors were informed by letter about the nature and purpose of the study, and written informed consent was provided. The study protocols were approved by the Ethics Committee of the Hospital Puerta de Hierro (Madrid, Spain), the Bioethics Committee of the National Research Council (Madrid, Spain) and the Committee for Research Involving Human Subjects at University of Cádiz (Cádiz, Spain).

\section{Measurements}

Pubertal development

After a brief visual observation, the participants self-classified in one of the five stages of pubertal development according to Tanner. ${ }^{17}$ To do this, breast development in girls and genital development in boys was used.

\section{Anthropometric and body composition indices}

Harmonisation and standardisation of anthropometric and body composition indices used to assess body composition in the UP\&DOWN study were strictly controlled. ${ }^{16}$ Anthropometric data included body mass, height, waist and NC and triceps and subscapular skinfold thicknesses. Body mass was measured with an electronic scale (Type SECA 861; range, 0.05-130 kg; precision, $0.05 \mathrm{~kg}$ ), and height was measured in the Frankfort plane with a telescopic stature-measuring instrument (Type SECA 225; range, $60-200 \mathrm{~cm}$; precision, $1 \mathrm{~mm}$ ). WC was measured with a non-elastic tape (SECA 200; range, $0-150 \mathrm{~cm}$; precision, $1 \mathrm{~mm}$ ), at the level of the natural waist, in a horizontal plane, which is the narrowest part of the torso, as seen from a front view. NC was assessed with the participants standing in an erect position, hanging the arms freely and keeping the head aligned in the Frankfort horizontal plane. The superior border of a non-elastic tape measure (SECA 200; range, $0-150 \mathrm{~cm}$; precision, $1 \mathrm{~mm}$ ) was placed just below the laryngeal prominence and applied perpendicular to the long axis of the neck. ${ }^{18}$ Triceps and subscapular skinfold thickness were measured on the non-dominant side of the body with a Holtain calliper (range, $0-40 \mathrm{~mm}$; precision, $0.2 \mathrm{~mm}$ ) according to Lohman's anthropometric standardisation reference manual. ${ }^{19}$ The measurements were carried out twice, but not consecutively, and the mean value of the two measurements was used in the analyses. BFP was calculated from triceps and subscapular skinfold thicknesses by using the equations developed by Slaughter et al. ${ }^{20}$

BMI was calculated as body mass/height squared $(\mathrm{kg} /$ $\mathrm{m}^{2}$ ) and participants were categorised as underweight/ normal weight and overweight/obese following international cut-off points. ${ }^{21}$ WHtR was computed from the original anthropometric index (waist/height). Fat mass index (FMI) was computed dividing BFP by height squared $\left(\mathrm{m}^{2}\right)$.

\section{Blood pressure}

Systolic and diastolic blood pressure (SBP and DBP, respectively) were measured by a validated digital automatic blood pressure monitor (Omron M6, Omron Health Care, Kyoto, Japan) according to the International Protocol of the European Society of Hypertension. ${ }^{22}$ 
The participants sat on a chair quietly for 5 min before the measurements were conducted on the left arm in an extended position. Two measures were taken 1-2 min apart. An additional measurement was performed if the first two readings differed in $>5 \mathrm{~mm} \mathrm{Hg}$, and the farthest value was removed. Average values $(\mathrm{mm} \mathrm{Hg})$ were calculated separately for SBP and DBP.

\section{Cardiorespiratory fitness}

Twenty-metre shuttle run test was used to assess cardiorespiratory fitness, according to the ALPHA health-related fitness test battery protocol. ${ }^{6}$ The equation reported by Léger $e t a t^{23}$ was used to estimate the maximum oxygen consumption $\left(\mathrm{VO}_{2 \max }, \mathrm{mL} / \mathrm{kg} / \mathrm{min}\right)$.

\section{Blood sampling}

A fasting blood sample was obtained from the cubital vein early in the morning at the schools. Drawn from each subject were $13.5 \mathrm{~mL}$ of blood, and $3.5 \mathrm{~mL}$ of them (anticoagulated blood in EDTA) were analysed to obtain haemogram data. The remainder blood (dried gel and sodium citrate) was centrifuged; serum and plasma were removed and then frozen at $-80^{\circ} \mathrm{C}$ to be analysed later. Serum lipid triglycerides (TG), total cholesterol (TC), high-density lipoprotein cholesterol (HDL-c), low-density lipoprotein cholesterol (LDL-c), glucose and total proteins as CVD risk factors were analysed by enzymatic colourimetric methods (Olympus AU2700 Analyzer; Olympus UK, Watford, UK).

The following inflammatory markers were analysed by turbidimetry (Olympus AU2700 Analyzer; Olympus UK, Watford, UK): serum complement factors C-3 (C3) C-4 (C4) and serum $\mathrm{C}$ reactive protein (CRP). The coefficients of variation (interassay precision) were less than $2 \%$ for all proteins (1.39\% for C3, $1.19 \%$ for C4\% and $1.90 \%$ for CRP). Detection limits (sensitivity) for the analyses were $0.01 \mathrm{~g} / \mathrm{L}$ for $\mathrm{C} 3,0.002 \mathrm{~g} / \mathrm{L}$ for $\mathrm{C} 4$ and $0.007 \mathrm{mg} / \mathrm{L}$ for CRP. Adiponectin, leptin, interleukin 6 (IL-6) and tumour necrosis factor alpha (TNF- $\alpha$ ) were quantified by multiple analyte profiling (xMAP) technology (xMAP Techonology; Luminex, Austin, Texas, USA) using a kit (5+1) plex: 171-A7003M Bio-plex Pro Human Diabetes Adiponectin Assay; YB0000002Y Bio-Plex Human Diabetes 3-Plex Assay; 171D50001 Bio-Plex Human Cytokine Stds; 171B5006M Bio-Plex Human IL-6 set; 171B5026M Bio-Plex Human TNF-alpha set. Visfatin values were determined by ELISA (Human visfatin Elisa kit; Cusabio Biotech, Wuhan, Hubei, China). Sensitivity for the analyses were $0.156 \mathrm{ng} / \mathrm{mL}$, the coefficients of variation were less than $8 \%$ for intra-assay precision and less than $10 \%$ for inter-assay precision.

Insulin resistance was calculated through the homoeostasis model assessment (HOMA) score as: (insulin $(\mathrm{mLU} / \mathrm{mL}) \times$ glucose $(\mathrm{mmol} / \mathrm{L})) / 22.5 .^{24}$

\section{Clustered CVD risk factors}

A cluster of CVD risk factors by sex and age groups was constructed. For that purpose, standardised normalised indices $(z$-score $=($ value-mean $) / \mathrm{SD})$ of the subsequent single CVD risk factors were computed: metabolic syndrome risk factors (ie, SBP, DBP, TC / HDL-c and TG), HOMA, inflammatory markers (ie, CRP, C-3, C-4, IL-6, leptin and adiponectin) and $\mathrm{VO}_{2 \max }$. The $\mathrm{VO}_{2 \max }$-score was inverted, because higher cardiorespiratory fitness is associated with lower fatness. Finally, all the z-scores were summed. LDL-c, TNF- $\alpha$ and visfatin were not included in the cluster because they did not show association with anthropometric nor body composition indices.

\section{Statistical analysis}

Anthropometric and body composition indices and cardiovascular markers are sex dependent; therefore, boys and girls were analysed separately. Descriptive data are shown as mean and SD unless otherwise indicated. The Studen $t^{\prime}$ s $t$-test was used to test differences in sociodemographic and clinical characteristics by sex, except for the Tanner stage, which was analysed by $\chi^{2}$ test. Pearson's correlation coefficients were obtained to analyse the association between $\mathrm{NC}$ and the other anthropometric and body composition indices (BMI, WC, WHtR, BFP and FMI) and the association between all anthropometric and body composition indices and single CVD risk factors. To test the association of single and cluster CVD risk factors with anthropometric and body composition indices, adjusted multiple linear regression analyses were performed. Single and clustered CVD risk factors were entered as dependent variables and anthropometric and body composition indices as independent variables in separate models.

To predict specific NC cut-off values for overweight and obesity, a linear regression analysis following a stepwise selection procedure for the derivation of prediction equation models including $\mathrm{NC}$ as dependent variable and BMI, WC and BFP as independent variables in separate models were performed. In the prediction equations, Cole's BMI, ${ }^{21}$ Katzmarzyk's WC $^{25}$ and McCarthy's $\mathrm{BFP}^{26}$ cut-off values for overweight/obesity to obtain the corresponding NC cut-off values were used. These are optimal threshold values for predicting high-risk groups to be used in the white population worldwide. All models were controlled for age and Tanner stage. The statistical analyses were performed using the Statistical Package for the Social Sciences V.22.0 (IBM SPSS Statistics for Windows), and the statistical significance was set at $\mathrm{p}<0.05$.

\section{RESULTS}

The characteristics of the study sample are presented in table 1. Boys presented higher values in Tanner stage, body mass, height, NC, WC, WHtR, $\mathrm{VO}_{2 \max }$ and SBP than girls (all, $\mathrm{p}<0.05)$. However, BFP, FMI, DBP, HOMA, leptin and adiponectin were significantly higher in girls compared with boys (all, p<0.05). 32.7\%, 38.7\%, 16\% and $37 \%$ of insulin, $\mathrm{C}$ reactive protein, TNF- $\alpha$ and visfatin 
Table 1 Descriptive characteristics of the population sample

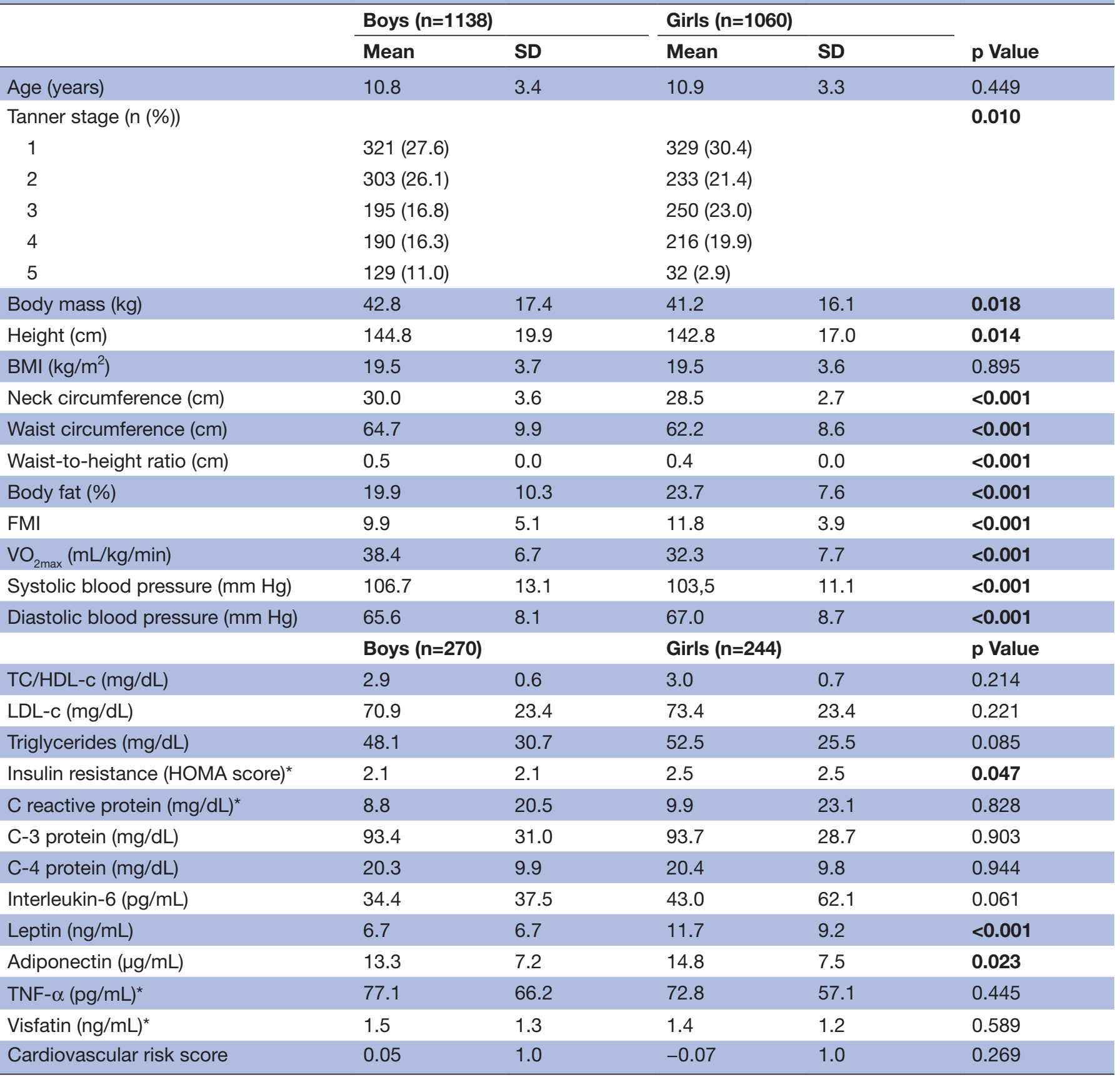

Results are showed as mean \pm SD (SD).

Sex differences with a $p$ value of $<0.05$ are marked as bold.

${ }^{*} 32.7 \%, 38.7 \%, 16 \%$ and $37 \%$ of insulin, $C$ reactive protein, TNF- $\alpha$ and visfatin sample, respectively, were below detection threshold and were not included in the analyses.

$\mathrm{VO}_{2 \max }$, maximum oxygen consumption; BMI, body mass index; FMI, fat mass index; HOMA, homoeostasis model assessment; LDL, lowdensity lipoprotein cholesterol; TC/HDL, total cholesterol/ high-density lipoprotein cholesterol; TNF- $\alpha$, tumour necrosis factor alpha. $\mathrm{VO}_{2 \max }$ maximum oxygen consumption.

sample, respectively, were below detection threshold and were not included in the final analyses.

Table 2 shows correlation coefficients between NC and BMI, WC, WHtR, BFP and FMI by sex. NC was positively correlated with all anthropometric and body composition indices in both, boys and girls (all, $\mathrm{p} \leq 0.001$ ). Correlations were stronger with $\mathrm{WC}(\mathrm{r}=0.864$ in boys, $\mathrm{r}=0.851$ in girls) and BMI ( $\mathrm{r}=0.754$ in boys, $\mathrm{r}=0.799$ in girls).
Table 3 shows bivariate correlations between all anthropometric and body composition indices and CVD risk factors by sex. Overall, all anthropometric and body composition indices were correlated with most single CVD risk factors, with higher correlation coefficients in boys than girls (all, $\mathrm{p} \leq 0.05$ ). More specifically, $\mathrm{NC}$ was negatively correlated with $\mathrm{VO}_{2 \max }$ $(\mathrm{r}=-0.481, \mathrm{p}<0.001$ for boys; $\mathrm{r}=-0.672, \mathrm{p}<0.001$ for 
Table 2 Correlations coefficients of neck circumference with BMI, WC, WtHR, BFP and FMI

\begin{tabular}{|c|c|c|c|c|}
\hline \multicolumn{5}{|c|}{ Neck circumference } \\
\hline & \multicolumn{2}{|c|}{ Boys $(n=1138)$} & \multicolumn{2}{|c|}{ Girls $(n=1060)$} \\
\hline & $r$ & p Value & $r$ & p Value \\
\hline $\mathrm{BMI}\left(\mathrm{kg} / \mathrm{m}^{2}\right)$ & 0.754 & $<0.001$ & 0.799 & $<0.001$ \\
\hline WC (cm) & 0.864 & $<0.001$ & 0.851 & $<0.001$ \\
\hline WHtR (cm) & 0.610 & 0.001 & 0.621 & $<0.001$ \\
\hline BFP (\%) & 0.552 & $<0.001$ & 0.648 & $<0.001$ \\
\hline FMI & 0.494 & $<0.001$ & 0.474 & $<0.001$ \\
\hline
\end{tabular}

Correlations with a $p$ value of $<0.05$ are marked as bold. BMI, body mass index; BFP, body fat percentage; FMI, fat mass index; WC, waist circumference; WHtR, waist to height ratio.

girls), positively correlated with SBP, DBP, TG, HOMA, C-3, C-4, leptin and adiponectin in both sexes ( $\mathrm{r}$ from 0.167 to 0.419 ; all, $\mathrm{p}<0.01$ ), and with TC/HDL-c, LDL-c, CRP and visfatin only in boys ( $\mathrm{r}$ from 0.243 to 0.388 ; all, $\mathrm{p}<0.001)$.

The associations between neck circumference and single and clustered CVD risk factors are presented in table 4. $\mathrm{NC}$ was negatively associated with $\mathrm{VO}_{2 \max }$ $\left(\mathrm{R}^{2}=0.231, \mathrm{p}<0.001\right.$ for boys; $\mathrm{R}^{2}=0.018, \mathrm{p}<0.001$ for girls), and positively associated with SBP, DBP, TC/ HDL-c, TG, HOMA, C-3, C-4, leptin, adiponectin and clustered CVD risk factor in both sexes $\left(R^{2}\right.$ from 0.035 to $0.353, \mathrm{p}<0.01$ for boys; $\mathrm{R}^{2}$ from 0.024 to 0.215 , $\mathrm{p}<0.001$ for girls). Moreover, NC was positively associated with CRP, LDL-c and visfatin only in boys $\left(\mathrm{R}^{2}\right.$ from 0.013 to $0.107, \mathrm{p}<0.05)$. Overall, the association of CVD risk factors with the other anthropometric and body composition indices presented similar results (see online supplementary file 1 ). When the variables with values below the detection levels (ie, insulin, CRP, TNF- $\alpha$ and visfatin) were included in the analyses of sensitivity, before natural log transformation, the associations aforementioned remained unchanged (data not shown). The associations Stepwise regression analyses were conducted to get specific NC cut-off values for overweight/obesity based on BMI, WC and BFP values (table 5). Results showed very similar NC cut-off values for boys and girls with the same age, independently of the criteria used to classify children and adolescents as normal weight or overweight/obese. Moreover, cut-off values increase with age and are higher in boys than girls. The prediction equations for NC cut-off values are presented below:

$\mathrm{NC}=13.631+0.466 \times \mathrm{BMI}+0.668 \times$ age $\left(\mathrm{R}^{2}=0.864\right.$ and $\left.\mathrm{SEE}=1.439\right)$ for boys $\mathrm{NC}=15.656+0.452 \times \mathrm{BMI}+0.365 \times$ age $\left(\mathrm{R}^{2}=0.796\right.$ and $\left.\mathrm{SEE}=1.428\right)$ for girls $\mathrm{NC}=10.735+0.210 \times \mathrm{WC}+0.520 \times$ age $\left(\mathrm{R}^{2}=0.877\right.$ and $\left.\mathrm{SEE}=1.367\right)$ for boys $\mathrm{NC}=11.825+0.212 \times \mathrm{WC}+0.315 \times$ age $\left(\mathrm{R}^{2}=0.825\right.$ and $\left.\mathrm{SEE}=1.189\right)$ for girls $\mathrm{NC}=18.364+0.106 \times \mathrm{BFP}+0.872 \times$ age $\left(\mathrm{R}^{2}=0.798\right.$ and $\left.\mathrm{SEE}=1.729\right)$ for boys $\mathrm{NC}=19.107+0.172 \times \mathrm{BFP}+0.480 \times$ age $\left(\mathrm{R}^{2}=0.726\right.$ and $\left.\mathrm{SEE}=1.484\right)$ for girls

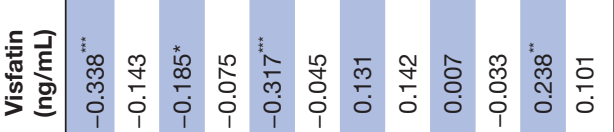

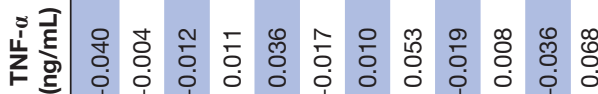

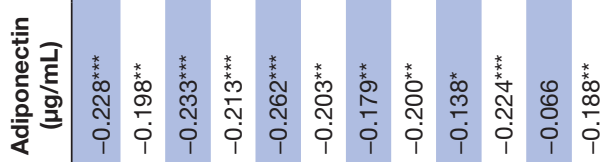

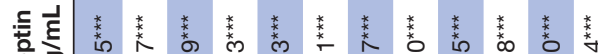

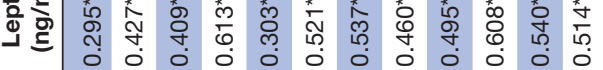

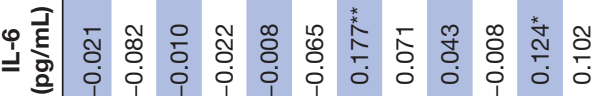

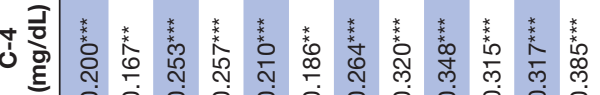

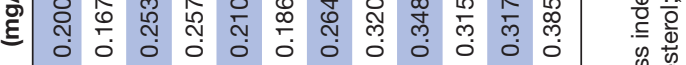

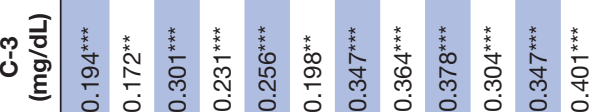

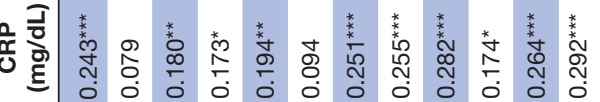

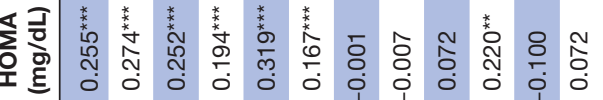

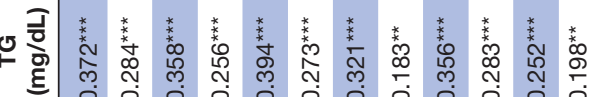

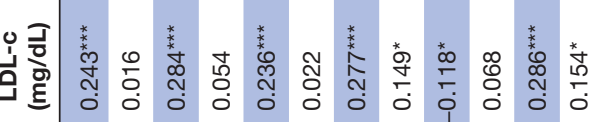

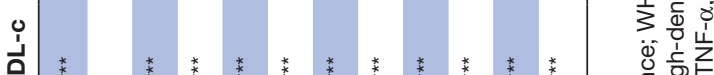

定

O

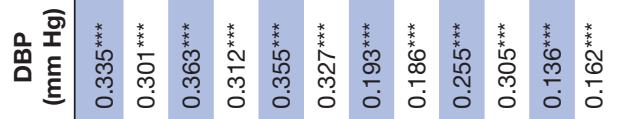

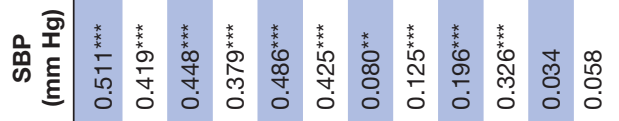

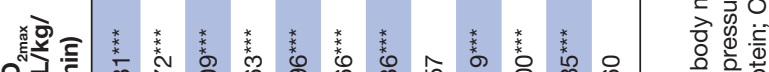

P

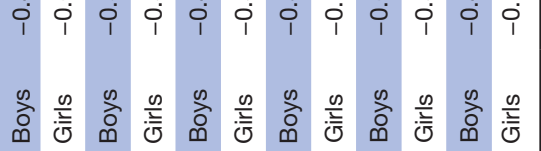

$\overline{\bar{\delta}} \overline{\mathrm{i}} \mathrm{\delta}$ 응

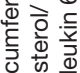

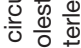

菏

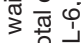

0

30.

잉뭉ㅎㅁ

$.5 \mathrm{O}$

है

ర్

의의

v

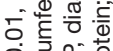

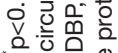

- 둥.

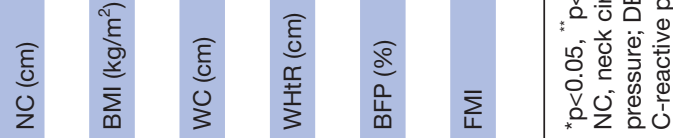


Table 4 Multiple linear regression analyses of single and cluster cardiovascular risk score with neck circumference

\begin{tabular}{|c|c|c|c|c|c|c|c|c|c|}
\hline & \multicolumn{5}{|c|}{ Boys } & \multicolumn{4}{|c|}{ Girls } \\
\hline & $\mathbf{n}$ & Adjusted $\mathrm{R}^{2}$ & $\beta$ & SE & $p$ Value & Adjusted $\mathbf{R}^{2}$ & $\beta$ & SE & p Value \\
\hline Dependent variables & & & & & Neck cir & umference & & & \\
\hline $\mathrm{VO}_{2 \max }(\mathrm{mL} / \mathrm{kg} / \mathrm{min})$ & 2146 & 0.231 & -1.173 & 0.062 & $<0.001$ & 0.018 & -0.467 & 0.081 & $<0.001$ \\
\hline $\mathrm{SBP}(\mathrm{mm} \mathrm{Hg})$ & 2191 & 0.353 & 2.526 & 0.155 & $<0.001$ & 0.353 & 2.526 & 0.155 & $<0.001$ \\
\hline $\mathrm{DBP}(\mathrm{mm} \mathrm{Hg})$ & 2191 & 0.113 & 1.195 & 0.111 & $<0.001$ & 0.089 & 1.216 & 0.133 & $<0.001$ \\
\hline $\mathrm{TC} / \mathrm{HDL}-\mathrm{c}(\mathrm{mg} / \mathrm{dL})$ & 514 & 0.098 & 0.098 & 0.015 & $<0.001$ & 0.048 & 0.073 & 0.019 & $<0.001$ \\
\hline LDL-c (mg/dL) & 513 & 0.013 & 1.377 & 0.663 & 0.039 & 0.007 & -0.844 & 0.516 & 0.103 \\
\hline Triglycerides (mg/dL) & 514 & 0.038 & 1.669 & 0.490 & $<0.001$ & 0.042 & 1.799 & 0.553 & $<0.001$ \\
\hline HOMA score & 342 & 0.169 & 0.256 & 0.043 & $<0.001$ & 0.073 & 0.604 & 0.160 & $<0.001$ \\
\hline $\mathrm{CRP}(\mathrm{mg} / \mathrm{dL})$ & 315 & 0.055 & 0.351 & 0.094 & $<0.001$ & $<0.001$ & -0.092 & 0.094 & 0.328 \\
\hline C-3 protein (mg/dL) & 514 & 0.035 & 3.164 & 0.728 & $<0.001$ & 0.026 & 1.630 & 0.557 & 0.004 \\
\hline C-4 protein (mg/dL) & 514 & 0.037 & 0.478 & 0.129 & $<0.001$ & 0.024 & 0.539 & 0.189 & 0.005 \\
\hline IL-6 (pg/mL) & 502 & $<0.001$ & -0.200 & 0.527 & 0.705 & 0.003 & -1.552 & 1.139 & 0.174 \\
\hline Leptin (ng/mL) & 499 & 0.060 & 713.142 & 155.007 & $<0.001$ & 0.179 & 1927.779 & 252.179 & $<0.001$ \\
\hline Adiponectin ( $\mu \mathrm{g} / \mathrm{mL})$ & 506 & 0.049 & -0.357 & 0.084 & $<0.001$ & 0.036 & -0.463 & 0.138 & $<0.001$ \\
\hline TNF- $\alpha(\mathrm{pg} / \mathrm{mL})$ & 478 & $<0.001$ & 1.058 & 1.182 & 0.539 & 0.016 & -2.052 & 3.976 & 0.413 \\
\hline Visfatin $(\mathrm{ng} / \mathrm{mL})$ & 324 & 0.107 & -0.100 & 0.025 & $<0.001$ & 0.012 & -0.046 & 0.030 & 0.124 \\
\hline $\begin{array}{l}\text { Cardiovascular risk } \\
\text { score }\end{array}$ & 315 & 0.130 & 0.287 & 0.103 & $<0.001$ & 0.207 & 0.834 & 0.248 & $<0.001$ \\
\hline
\end{tabular}

Associations with a $\mathrm{p}$ value of $<0.05$ are marked as bold.

All analyses were controlled for age and Tanner stage.

$\beta$, estimated unstandardized regression coefficient; SE, standard error.

$\mathrm{VO}_{2 \max }$, maximum oxygen consumption; SBP, systolic blood pressure; DBP, diastolic blood pressure; TC/HDL-c, total cholesterol/ high-density lipoprotein cholesterol; LDL-c, low-density lipoprotein cholesterol; TG, triglycerides; HOMA, homeostasis model assessment; IL-6, interleukin

6; TNF- $\alpha$, tumour necrosis factor alpha.

Table 5 Neck circumference cut-off values for determining overweight/obese youth with BMI, WC and BFP

\begin{tabular}{|c|c|c|c|c|c|c|}
\hline \multirow[b]{2}{*}{ Age } & \multicolumn{2}{|c|}{$\begin{array}{l}\text { Using Cole's } \\
\text { BMI cut-off } \\
\text { values }\end{array}$} & \multicolumn{2}{|c|}{$\begin{array}{l}\text { Using } \\
\text { Katzmarzyk's } \\
\text { WC cut-off } \\
\text { values }\end{array}$} & \multicolumn{2}{|c|}{$\begin{array}{c}\text { Using } \\
\text { McCarthy's BFP } \\
\text { cut-off values }\end{array}$} \\
\hline & Boys & Girls & Boys & Girls & Boys & Girls \\
\hline 6 & 25.8 & 25.7 & 25.3 & 25.0 & 25.6 & 25.9 \\
\hline 7 & 26.7 & 26.2 & 26.2 & 25.7 & 26.6 & 26.6 \\
\hline 8 & 27.6 & 26.9 & 27.1 & 26.6 & 27.6 & 27.3 \\
\hline 9 & 28.5 & 27.5 & 28.3 & 27.5 & 28.5 & 28.0 \\
\hline 10 & 29.5 & 28.3 & 29.5 & 28.3 & 29.5 & 28.7 \\
\hline 11 & 30.5 & 29.0 & 30.6 & 29.2 & 30.4 & 29.3 \\
\hline 12 & 31.5 & 29.8 & 31.8 & 29.9 & 31.3 & 29.9 \\
\hline 13 & 32.4 & 30.6 & 32.9 & 30.6 & 32.1 & 30.5 \\
\hline 14 & 33.4 & 31.3 & 33.9 & 31.3 & 32.9 & 31.0 \\
\hline 15 & 34.4 & 31.9 & 34.7 & 31.6 & 33.7 & 31.5 \\
\hline 16 & 35.3 & 32.5 & 35.4 & 32.0 & 34.5 & 32.0 \\
\hline 17 & 36.2 & 32.9 & 36.1 & 32.2 & 35.4 & 32.5 \\
\hline 18 & 37.1 & 33.5 & 36.7 & 32.5 & 36.3 & 33.1 \\
\hline
\end{tabular}

BFP, body fat percentage; BMI, body mass index; WC, waist circumference.

\section{DISCUSSION}

The main findings indicate that: (1) NC is strong and positively associated with well-known indices of anthropometric and body composition, such as BMI, WC, BFP, WHtR and FMI; (2i) NC is one of the strongest indices associated with single and clustered CVD risk factors; (3) sex and age-specific NC cut-off values are provided to classify children and adolescents as normal weight or overweight/obese.

Comparison of NC with well-known anthropometric and body composition indices

BMI is the most common anthropometric index used to determine overweight and obesity not only in children and adolescents but also in adults. BMI has become a very popular screening tool for overweight and obesity due to its simplicity and ease. However, it is becoming increasingly clear that it is not a good proxy for regional adiposity. ${ }^{27}$ Regional deposition of fat is a better predictor of some obesity-related complications, such as metabolic disorders and CVD risk factors. ${ }^{28} \mathrm{In}$ this regard, WC seems to be a better anthropometric index in children and adolescents. ${ }^{29}$ On the other hand, $\mathrm{WH} \mathrm{tR}^{30}$ and $\mathrm{FMI}^{31}$ have been proposed as a marker of adiposity in children and adolescents, however, these indices have been built in analogy with BMI. 
Recently, NC has been proposed as a surrogate marker of regional obesity in children and adolescents. ${ }^{78}$ These studies reported strong correlations between NC and BMI and WC $(r>0.7)$. Concurring with these studies, NC was correlated with a larger number of anthropometric and body composition indices (ie, BMI, WC, WHtR, BFP and FMI). More specifically, NC was highly correlated with $\mathrm{WC}$ and BMI and in both sexes, which confirms its use as a screening tool for identifying overweight/obese children and adolescents. NC is a simple, quick and low-cost method that requires less effort from both the examiner and the examinee than other anthropometric and body composition methods. NC has shown very good inter-rater and intrarater reliability ${ }^{32}$ and unlike WC, NC is not influenced by the timing of measurement (eg, preprandial and postprandial period; measurement at the end of a gentle expiration as suggested for WC). Additionally, this technique does not require the patient to remove his/her clothing to obtain a more accurate measurement. Finally, the measurement of NC may be more socially acceptable and convenient for overweight and obese children, thus making this measurement more tolerable for them.

\section{NC and single CVD risk factors}

There is evidence to support that NC is a screening tool for identifying CVD in adults in worldwide. ${ }^{33}$ However, little is known about the association between $\mathrm{NC}$ and CVD risk factors in children and adolescents. In the present study, NC, as well as all other anthropometric and body composition indices, was associated with cardiometabolic syndrome risk factors. Androutsos et $a l^{10}$ and Kurtoglu et $a^{\theta}$ also observed that increases in NC were associated with cardiometabolic syndrome risk factors in Greek and Turkish normal or overweight/obese children and adolescents. Moreover, Guo et $a l^{34}$ showed that NC could predict prehypertension in Chinese normal weight children and adolescents, but not in those overweight and obese. It is widely accepted that obesity is associated with metabolic disorders and CVD risk factors both in youth and adulthood. ${ }^{35}$ Free fatty acid concentration is related with the development of CVD risk factors. It has been demonstrated that upper body subcutaneous fat is responsible for a much larger proportion of systemic free fatty acid release than visceral fat, particularly in obese individuals. ${ }^{36}$ Moreover, The Framingham Heart Study showed that NC was associated with CVD risk factors even after adjustment for visceral adipose tissue and BMI, suggesting that upper body subcutaneous fat may be a unique fat depot conferring additional cardiovascular risk above and beyond central body fat. ${ }^{37}$ These previous results are in line with this study findings, suggesting that thicker NC is associated with greater risk of CVD.

Inflammatory markers have been proposed as new emerging CVD risk factors. ${ }^{38}$ Indeed, persistent low-grade inflammation in children, especially in obese, may increase the risk of metabolic and cardiovascular events in later life and play a role in the pathogenesis of atherosclerosis. ${ }^{39}$ Thus, inflammatory markers have a potential interest for paediatric CVD risk factor control and future preventive strategies. Overall, obesity in children and adolescents is associated with increased CRP, C-3, C-4 and leptin levels and decreased adiponectin levels, ${ }^{39-41}$ which concurs with the results of the present study. To the best of our knowledge, no studies have been published analysing the associations between $\mathrm{NC}$ and inflammatory markers in children and adolescents. In addition, data with WHtR, $\mathrm{BFP}$ and FMI are sparse. In the present study, similar associations were found among all anthropometric and body composition indices and inflammatory markers. There is controversy in the relationship between some inflammatory markers (ie, plasma IL-6, TNF- $\alpha$ and visfatin) and obesity, with some studies reporting positive ${ }^{40} 42$ or no associations ${ }^{40}{ }^{41}$ with obesity. In the present study, IL-6 and visfatin were associated with WHtR and FMI in both sexes and only with NC in boys. However, no associations among all anthropometric and body composition indices and TNF- $\alpha$. Differences among studies might be due, as Jaleel $e t a l^{40}$ suggested, to differences in degrees of maturation, sex distribution and ethnic specificity. Further studies are needed to clarify this association.

\section{NC and clustered CVD risk factors}

A clustered CVD risk factors reflects cardiovascular health better than single CVD risk factors and might, to some extent, compensate for the day-to-day fluctuations in the single risk factors. ${ }^{43}$ Even if none of the participants suffer from clinical disease, clustered risk is certainly an undesirable condition, and it has been shown to track into young adulthood. ${ }^{44}$ The results of the current study showed that $\mathrm{NC}$ was associated with clustered CVD risk factors in boys and girls.

Previous studies found a strong association between some anthropometric and body composition indices and clustered CVD risk factors. ${ }^{11}{ }^{14} 43$ However, to the best of our knowledge this is the first study in examining the association between $\mathrm{NC}$ and a cluster of CVD risk factors and also the first study in including a large number of inflammatory markers (ie, CRP, C-3, C-4, IL-6, leptin and adiponectin) as part of the cluster, as recently suggested, due to its relation to clustering of CVD risk factors at early ages. ${ }^{38}$ In addition, $\mathrm{VO}_{2 \max }$ was also included in the cluster as performed in previous studies ${ }^{43}$ as it is considered a CVD risk factor in children and adolescents. Andersen $e t$ $a t^{43}$ previously followed this strategy and it is noteworthy that their findings were consistent with those of the present study.

\section{Establishment of NC cut-offs to identify children and adolescents with overweight/obesity}

Results from the present study showed that NC could be used as a screening tool to identify children and adolescents at CVD risk. Therefore, providing with sex and age-specific cut-off values to classify children and adolescents as normal weight or overweight/obese is of relevance from a public health and clinical perspective. The criteria used to classify children and adolescents as normal 
weight or overweight/obese were based on $\mathrm{BMI},{ }^{21} \mathrm{WC}^{25}$ and $\mathrm{BFP}^{26}$ widely accepted cut-off values in children and adolescents. The explained variances of the full models were high $(86 \%$ for boys and $80 \%$ for girls with BMI, $88 \%$ for boys and $83 \%$ for girls with WC and $80 \%$ for boys and $73 \%$ for girls with BFP), suggesting that NC cut-off values can be established according to BMI, WC and BFP values. The results show NC cut-offs that increase with age and are higher in boys than girls. In addition, cut-offs for the same age are very similar independently of the criteria used to classify children and adolescents as normal weight or overweight/obese. It is known that body fat distribution and its metabolic effects are different in men and women with sex hormones playing a role in this difference. However, a definite cause has not been established. ${ }^{45}$ These results are consistent with those reported in other study based only in BMI cut-off values. ${ }^{78}$ To note is that NC cut-off values from the current study were slightly lower than those of previous studies ${ }^{78}$ which may be due to ethnic differences. To our knowledge, this is the first study that establishes NC cut-offs for overweight/ obesity according to BMI, WC and BFP values in the same sample.

\section{CONCLUSIONS}

In conclusion, $\mathrm{NC}$ was positively associated with other anthropometric and body composition indices, single and clustered CVD risk factors. NC is a simple, low-cost and practical screening tool of excess of upper body obesity and CVD risk factors in children and adolescents. For this purpose, sex and age-specific thresholds to classify children and adolescents as normal weight or overweight/obese are provided. It might be interesting to test in prospective studies whether NC cut off points presented in the current study are predictors of cardiovascular disease risk factors in adulthood.

\section{Author affiliations \\ ${ }^{1}$ Department of Physical Education, Faculty of Education Sciences, University of Cádiz, Puerto Real, Spain \\ ${ }^{2}$ Children's Health and Exercise Research Centre (CHERC), Sport and Health Sciences, University of Exeter, Exeter, UK \\ ${ }^{3}$ GENUD 'Growth, Exercise, Nutrition and Development' Research Group, University of Zaragoza, Zaragoza, Spain \\ ${ }^{4}$ Immunonutrition Group, Institute of Food Science, Technology and Nutrition (ICTAN), Spanish National Research Council (CSIC), Madrid, Spain \\ ${ }^{5}$ Department of Physical Education, Sports and Human Movement, Faculty of Teacher Training and Education, Autonomous University of Madrid, Madrid, Spain ${ }^{6}$ PROFITH "PROmoting FITness and Health through physical activity" Research Group, Department of Physical Education and Sport, Faculty of Sport Sciences, University of Granada, Granada, Spain}

Acknowledgements We gratefully acknowledge all the study participants for their collaboration

Collaborators Coordinator: Ascension Marcos. Principal investigators: Ascension Marcos, Jose Castro Piñero, Oscar L Veiga and Fernando Bandres. Scientific coordinators: David Martinez Gomez (chair), Jonatan R Ruiz (cochair), Ana Carbonell Baeza, Sonia Gomez Martinez and Catalina Santiago. Spanish National Research Council: Ascension Marcos, Sonia Gomez Martinez, Esther Nova, Ligia Esperanza Diaz, Belen Zapatera, Ana M Veses, Aurora Hernandez and Alina Gheorghe. University of Cadiz: José Castro Piñero, Jesus Mora Vicente, Jose LGonzalez
Montesinos, Julio Conde Caveda, Jonatan R Ruiz (University of Granada (UGR)), Francisco B Ortega (UGR), Carmen Padilla Moledo, Ana Carbonell Baeza, Palma Chillon (UGR), Jorge del Rosario Fernandez, Ana Gonzalez Galo, Gonzalo Bellvis Guerra, Alvaro Delgado Alfonso, Fernando Parrilla, Roque Gomez and Juan Gavala. Autonomous University of Madrid: Oscar L Veiga, H Ariel Villagra, Juan del Campo, Carlos Cordente (UPM), Mario Diaz, Carlos M Tejero, Aitor Acha, Jose M Moya, Alberto Sanz, David Martinez Gomez, Veronica Cabanas Sanchez, Gabriel Rodriguez Romo (UPM), Rocio Izquierdo, Laura Garcia Cervantes and Irene Esteban Cornejo. Complutense University of Madrid: Fernando Bandres, Alejandro Lucia (European University of Madrid (UEM)), Catalina Santiago (UEM) and Felix Gomez Gallego (UEM).

Contributors JCP, ADA, LGM and VSJ contributed to the concept and design of the study. JCP, LGM and VSJ contributed to the analysis and interpretation of the data. JCP, ADA, and VSJ contributed to drafting the manuscript. JCP, ADA, LGM, SGM, IEC OLV, AM and VSJ contributed to the conduct of the study and critically reviewed the manuscript. Final approval of the version to be published was obtained from each of the authors.

Funding This work was supported by the DEP 201021662 C04 00 (DEP 2010 21662 C04 01: DEP 201021662 C04 02: DEP 201021662 C04 03: DEP 2010 21662 C04 04) grant from the National Plan for Research: Development and Innovation (R+D+i) MICINN. We would like to thank all the members involved in the fieldwork.

Competing interests None declared.

Patient consent Obtained from guardian.

Ethics approval The study protocol was carried out according to the Declaration of Helsinki and was approved by the Ethics Committee of the Hospital Puerta de Hierro (Madrid, Spain), the Bioethics Committee of the National Research Council (Madrid, Spain) and the Committee for Research Involving Human Subjects at University of Cádiz (Cádiz, Spain).

Provenance and peer review Not commissioned; externally peer reviewed.

Open Access This is an Open Access article distributed in accordance with the Creative Commons Attribution Non Commercial (CC BY-NC 4.0) license, which permits others to distribute, remix, adapt, build upon this work non-commercially, and license their derivative works on different terms, provided the original work is properly cited and the use is non-commercial. See: http://creativecommons.org/ licenses/by-nc/4.0/

(c) Article author(s) (or their employer(s) unless otherwise stated in the text of the article) 2017. All rights reserved. No commercial use is permitted unless otherwise expressly granted.

\section{REFERENCES}

1. de Onis M, Blössner M, Borghi E. Global prevalence and trends of overweight and obesity among preschool children. Am J Clin Nutr 2010;92:1257-64.

2. $\mathrm{Ng} \mathrm{M}$, Fleming $\mathrm{T}$, Robinson $\mathrm{M}$, et al. Global, regional, and national prevalence of overweight and obesity in children and adults during 1980-2013: a systematic analysis for the global burden of disease study 2013. Lancet 2014;384:766-81.

3. Freedman DS, Mei Z, Srinivasan SR, et al. Cardiovascular risk factors and excess adiposity among overweight children and adolescents: the Bogalusa Heart Study. J Pediatr 2007;150:12-17.

4. Franks PW, Hanson RL, Knowler WC, et al. Childhood obesity, other cardiovascular risk factors, and premature death. N Engl J Med 2010;362:485-93.

5. von Bonsdorff MB, Törmäkangas T, Rantanen T, et al. Early life body mass trajectories and mortality in older age: findings from the Helsinki Birth Cohort Study. Ann Med 2015;47:1-6.

6. Ruiz JR, Castro-Piñero J, España-Romero V, et al. Field-based fitness assessment in young people: the ALPHA health-related fitness test battery for children and adolescents. Br J Sports Med 2011;45:518-24.

7. Nafiu OO, Burke C, Lee J, et al. Neck circumference as a screening measure for identifying children with high body mass index. Pediatrics 2010;126:e306-10.

8. Hatipoglu N, Mazicioglu MM, Kurtoglu S, et al. Neck circumference: an additional tool of screening overweight and obesity in childhood. Eur J Pediatr 2010;169:733-9.

9. Kurtoglu S, Hatipoglu N, Mazicioglu MM, et al. Neck circumference as a novel parameter to determine metabolic risk factors in obese children. Eur J Clin Invest 2012;42:623-30. 
10. Androutsos O, Grammatikaki E, Moschonis G, et al. Neck circumference: a useful screening tool of cardiovascular risk in children. Pediatr Obes 2012;7:187-95.

11. Gomez-Arbelaez D, Camacho PA, Cohen DD, et al. Neck circumference as a predictor of metabolic syndrome, insulin resistance and low-grade systemic inflammation in children: the ACFIES study. BMC Pediatr 2016;16:31.

12. Andersen LB, Bugge A, Dencker M, et al. The association between physical activity, physical fitness and development of metabolic disorders. Int J Pediatr Obes 2011;6 Suppl 1:29-34.

13. Lloyd-Jones DM. Cardiovascular risk prediction: basic concepts, current status, and future directions. Circulation 2010;121:1768-77.

14. Andersen LB, Müller K, Eiberg S, et al. Cytokines and clustered cardiovascular risk factors in children. Metabolism 2010;59:561-6.

15. Hansson GK. Inflammation, atherosclerosis, and coronary artery disease. N Engl J Med 2005;352:1685-95.

16. Castro-Piñero J, Carbonell-Baeza A, Martinez-Gomez D, et al. Follow-up in healthy schoolchildren and in adolescents with down syndrome: psycho-environmental and genetic determinants of physical activity and its impact on fitness, cardiovascular diseases, inflammatory biomarkers and mental health; the Up\&down study. BMC Public Health 2014;14:400.

17. Tanner J. Growth at adolescence. Oxford, United Kingdom: Blackwell, 1962

18. Centers for Disease Control and Prevention. National Health and Nutrition Examination survey (NHANES) anthropometry procedures Manual. 2009. http://www.cdc.gov/nchs/data/nhanes/nhanes_09_10/ BodyMeasures_09.pdf

19. Lohman TG, Roche AF, Matorell R. Anthropometric standardization reference manual. Champaingn, IL: Human Kinetics, 1991.

20. Slaughter MH, Lohman TG, Boileau RA, et al. Skinfold equations for estimation of body fatness in children and youth. Hum Biol 1988;60:709-23.

21. Cole TJ, Lobstein T. Extended international (IOTF) body mass index cut-offs for thinness, overweight and obesity. Pediatr Obes 2012;7:284-94

22. Topouchian JA, El Assaad MA, Orobinskaia LV, et al. Validation of two automatic devices for self-measurement of blood pressure according to the International Protocol of the European Society of hypertension: the Omron M6 (HEM-7001-E) and the Omron R7 (HEM 637-IT). Blood Press Monit 2006;11:165-71.

23. Léger LA, Mercier D, Gadoury C, et al. The multistage 20 metre shuttle run test for aerobic fitness. J Sports Sci 1988;6:93-101.

24. Matthews DR, Hosker JP, Rudenski AS, et al. Homeostasis model assessment: insulin resistance and beta-cell function from fasting plasma glucose and insulin concentrations in man. Diabetologia 1985;28:412-9.

25. Katzmarzyk PT, Srinivasan SR, Chen W, et al. Body mass index, waist circumference, and clustering of cardiovascular disease risk factors in a biracial sample of children and adolescents. Pediatrics 2004;114:e198-e205.

26. McCarthy HD, Cole TJ, Fry T, et al. Body fat reference curves for children. Int $J$ Obes 2006;30:598-602.
27. Walton C, Lees B, Crook D, et al. Body fat distribution, rather than overall adiposity, influences serum lipids and lipoproteins in healthy men independently of age. Am J Med 1995;99:459-64.

28. Kissebah AH, Krakower GR. Regional adiposity and morbidity. Physiol Rev 1994;74:761-811.

29. Savva SC, Tornaritis M, Savva ME, et al. Waist circumference and waist-to-height ratio are better predictors of cardiovascular disease risk factors in children than body mass index. Int $J$ Obes Relat Metab Disord 2000;24:1453-8.

30. Brambilla P, Bedogni G, Heo M, et al. Waist circumference-to-height ratio predicts adiposity better than body mass index in children and adolescents. Int J Obes 2013;37:943-6.

31. Freedman DS, Wang J, Maynard LM, et al. Relation of BMI to fat and fat-free mass among children and adolescents. Int $J$ Obes 2005:29:1-8.

32. LaBerge RC, Vaccani JP, Gow RM, et al. Inter- and intra-rater reliability of neck circumference measurements in children. Pediatr Pulmonol 2009;44:64-9.

33. Zhou JY, Ge H, Zhu MF, et al. Neck circumference as an independent predictive contributor to cardio-metabolic syndrome. Cardiovasc Diabetol 2013;12:76.

34. Guo X, Li Y, Sun G, et al. Prehypertension in children and adolescents: association with body weight and neck circumference. Intern Med 2012;51:23-7.

35. Biro FM, Wien M. Childhood obesity and adult morbidities. Am J Clin Nutr 2010;91:1499S-505.

36. Nielsen S, Guo Z, Johnson CM, et al. Splanchnic lipolysis in human obesity. J Clin Invest 2004;113:1582-8.

37. Preis SR, Massaro JM, Hoffmann U, et al. Neck circumference as a novel measure of cardiometabolic risk: the Framingham Heart study. $J$ Clin Endocrinol Metab 2010:95:3701-10.

38. Braunwald E. Biomarkers in heart failure. $N$ Engl $J$ Med 2008;358:2148-59.

39. Tam CS, Clément K, Baur LA, et al. Obesity and low-grade inflammation: a paediatric perspective. Obes Rev 2010;11:118-26.

40. Jaleel A, Aheed B, Jaleel S, et al. Association of adipokines with obesity in children and adolescents. Biomark Med 2013;7:731-5.

41. Steene-Johannessen J, Kolle E, Andersen LB, et al. Adiposity, aerobic fitness, muscle fitness, and markers of inflammation in children. Med Sci Sports Exerc 2013;45:714-21.

42. Ooi SQ, Chan RM, Poh LK, et al. Visfatin and its genetic variants are associated with obesity-related morbidities and cardiometabolic risk in severely obese children. Pediatr Obes 2014;9:81-91.

43. Andersen LB, Sardinha LB, Froberg K, et al. Fitness, fatness and clustering of cardiovascular risk factors in children from Denmark Estonia and Portugal: the European Youth Heart Study. Int J Pediatr Obes 2008;3 Suppl 1:58-66.

44. Andersen LB, Hasselstrøm H, Grønfeldt V, et al. The relationship between physical fitness and clustered risk, and tracking of clustered risk from adolescence to young adulthood: eight years follow-up in the danish youth and Sport Study. Int J Behav Nutr Phys Act 2004;1:6.

45. Santosa S, Jensen MD. Why are we shaped differently, and why does it matter? Am J Physiol Endocrinol Metab 2008;295:E53 $1-\mathrm{E} 535$. 
Correction: Neck circumference and clustered cardiovascular risk factors in children and adolescents: cross-sectional study

Castro-Piñero J, Delgado-Alfonso A, Gracia-Marco L The UP\&DOWN Study Group, et al. Neck circumference and clustered cardiovascular risk factors in children and adolescents: cross-sectional study. BMJ Open 2017;7:e016048. doi:10.1136/ bmjopen-2017-016048

An error in translating the results from the tables to the text has been included in this study. Statistical analysis was correct as well as the results shown in tables and figure. The correction of this error does not change the results or conclusions of the study, but for clarification, the following corrections are noted:

1. In Results section of the Abstract, ' $\mathrm{NC}$ was negatively associated with maximum oxygen consumption ( $\mathrm{R} 2=0.231, \mathrm{P}<0.001$ for boys; $\mathrm{R} 2=0.018, \mathrm{P}<0.001$ for girls) and positively associated with SBP, DBP, TC/HDL-c, TG, HOMA, complement factors C-3 and C-4, leptin, adiponectin and clustered CVD risk factor in both sexes (R2 from 0.035 to $0.353, \mathrm{P}<0.01$ for boys; $\mathrm{R} 2$ from 0.024 to $0.215, \mathrm{P}<0.001$ for girls). Moreover, NC was positively associated with serum $\mathrm{C}$ reactive protein, LDL-c and visfatin only in boys ( $\mathrm{R} 2$ from 0.013 to $0.107, \mathrm{P}<0.05$ ).' should read 'NC was negatively associated with maximum oxygen consumption ( $\mathrm{R} 2=0.231, \mathrm{P}<0.001$ for boys; R2=0.018, $\mathrm{P}<0.001$ for girls) and adiponectin ( $\mathrm{R} 2=0.049, \mathrm{P}<0.001$ for boys; $\mathrm{R} 2=0.036, \mathrm{P}<0.001$ for girls); and positively associated with SBP, DBP, TC/HDL-c, TG, HOMA, complement factors C-3 and C-4, leptin and clustered CVD risk factor in both sexes ( $\mathrm{R} 2$ from 0.035 to $0.353, \mathrm{P}<0.01$ for boys; $\mathrm{R} 2$ from 0.024 to 0.215 , $\mathrm{P}<0.001$ for girls). Moreover, $\mathrm{NC}$ was positively associated with serum $\mathrm{C}$ reactive protein and LDL-c only in boys (R2 from 0.013 to $0.055, \mathrm{P}<0.05$ )'.

2. In Clustered CVD risk factors measurement section of the Method, 'The VO2max z-score was inverted, because higher cardiorespiratory fitness is associated with lower fatness' should read 'The VO2max and adiponectin z-scores were inverted, because higher values of both are associated with lower fatness'.

3. Related to Table 3 of the Results, 'More specifically, $\mathrm{NC}$ was negatively correlated with VO2max ( $\mathrm{r}=-0.481, \mathrm{P}<0.001$ for boys; $\mathrm{r}=-0.672, \mathrm{P}<0.001$ for girls), positively correlated with SBP, DBP, TG, HOMA, C-3, C-4, leptin and adiponectin in both sexes ( $r$ from 0.167 to 0.419 ; all, $\mathrm{P}<0.01$ ), and with TC/HDL-c, LDL-c, CRP and visfatin only in boys ( $\mathrm{r}$ from 0.243 to 0.388 ; all, $\mathrm{P}<0.001$ ).' should read 'More specifically, $\mathrm{NC}$ was negatively correlated with $\mathrm{VO} 2 \mathrm{max}(\mathrm{r}=-0.481, \mathrm{P}<0.001$ for boys; $\mathrm{r}=-0.672$, $\mathrm{P}<0.001$ for girls), adiponectin ( $\mathrm{r}=-0.228, \mathrm{P}<0.001$ for boys; $\mathrm{r}=-0.198, \mathrm{P}<0.001$ for girls) and visfatin only in boys $(\mathrm{r}=-0.338, \mathrm{P}<0.001)$, and positively correlated with SBP, DBP, TG, HOMA, C-3, C-4 and leptin in both sexes ( $\mathrm{r}$ from 0.167 to 0.419 ; all, $\mathrm{P}<0.01$ ), and with TC/HDL-c, LDL-c and CRP only in boys ( $\mathrm{r}$ from 0.243 to 0.388 ; all, $\mathrm{P}<0.001)^{\prime}$.

4. Related to Table 4 of the Results, 'NC was negatively associated with VO2max ( $\mathrm{R} 2=0.231, \mathrm{P}<0.001$ for boys; $\mathrm{R} 2=0.018, \mathrm{P}<0.001$ for girls), and positively associated with SBP, DBP, TC/HDL-c, TG, HOMA, C-3, C-4, leptin, adiponectin and clustered CVD risk factor in both sexes ( $\mathrm{R} 2$ from 0.035 to $0.353, \mathrm{P}<0.01$ for boys; $\mathrm{R} 2$ from 0.024 to $0.215, \mathrm{P}<0.001$ for girls). Moreover, $\mathrm{NC}$ was positively associated with $\mathrm{CRP}$, LDL-c and visfatin only in boys ( $\mathrm{R} 2$ from 0.013 to 0.107 , $\mathrm{P}<0.05)$.' should read ' $\mathrm{NC}$ was negatively associated with maximum oxygen consumption ( $\mathrm{R} 2=0.231, \mathrm{P}<0.001$ for boys; $\mathrm{R} 2=0.018, \mathrm{P}<0.001$ for girls), adiponectin ( $\mathrm{R} 2=0.049, \mathrm{P}<0.001$ for boys; $\mathrm{R} 2=0.036, \mathrm{P}<0.001$ for girls) and visfatin only in boys $(\mathrm{R} 2=0.107, \mathrm{P}<0.001)$; and positively associated with SBP, DBP, TC/HDL-c, TG, HOMA, complement factors C-3 and C-4, leptin and clustered CVD risk factor in both sexes (R2 from 0.035 to 0.353 , $\mathrm{P}<0.01$ for boys; $\mathrm{R} 2$ from 0.024 to $0.215, \mathrm{P}<0.001$ for girls). Moreover, $\mathrm{NC}$ was positively associated with CRP and LDL-c only in boys ( $\mathrm{R} 2$ from 0.013 to $0.055, \mathrm{P}<0.05$ )'

5. In NC and single CVD risk factors section of Discussion 'In the present study, IL-6 and visfatin were associated with WHtR and FMI in both sexes and only with NC in 
boys' should read 'In the present study, IL-6 was associated with WHtR and FMI in boys only, whilst visfatin was associated with NC in boys only'

Open Access This is an Open Access article distributed in accordance with the terms of the Creative Commons Attribution (CC BY 4.0) license, which permits others to distribute, remix, adapt and build upon this work, for commercial use, provided the original work is properly cited. See: http://creativecommons.org/licenses/by/4.0/

C Article author(s) (or their employer(s) unless otherwise stated in the text of the article) 2018. All rights reserved. No commercial use is permitted unless otherwise expressly granted.

BMJ Open 2018;8:e016048corr1. doi:10.1136/bmjopen-2017-016048corr1

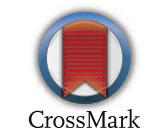

